\title{
Using Student-Centered Projects To Teach Mathematics Content Standards To Middle School Teachers II (The Second Course)
}

\author{
Carryn Bellomo, (E-mail: Carryn.Bellomo@unlv.edu), University Of Nevada
}

\begin{abstract}
Teaching and learning standards across the country are becoming more content driven, especially in mathematics. As such, it is essential to develop substantive college level math courses for preservice and in-service teachers. These courses should deliver mathematical content in a relevant way. Teachers must not only be proficient in their subject, but also recognize how to apply content meaningfully to student's lives. As part of a grant funded through the Department of Education in coordination with the Clark County School District, I have designed two college level courses that will deliver mathematical content standards to middle school teachers. These courses will help prepare teachers at the middle school level by focusing on mathematical content, making connections within the curriculum, using technology, and enhancing the role of mathematics in everyday life and problem solving. This paper extends the concepts provided in [1]. The primary purpose of this paper is to share with the academic community the projects used to develop content understanding in mathematics topics such as: spatial relationships, geometry, problem solving, reasoning, mathematical modeling, financial and economic analysis, and probability. This paper will present these projects, and tie them to mathematics standards outlined in the Clark County School District (and state of Nevada).
\end{abstract}

\section{OVERVIEW OF COURSE}

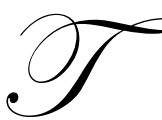

o provide Clark County School District (CCSD) seventh grade teachers with additional content knowledge and pedagogy that they may not have received during their pre-service training, the Seventh Grade Grant Program [2] creates a seventh grade mathematics cohort learning community. This grant has been a collaborative effort between faculty at the University of Nevada Las Vegas (UNLV), the CCSD Mathematics Coordinator and the Grant Project Facilitator. Cohort participants are provided with a sixteen hour summer mathematics workshop, three eight hour professional development seminars, and financial support for nine semester hours of identified university pedagogical content course work. Thus, the UNLV courses connected to the CCSD school mathematics standards for grades five through eight were borne - Mathematical Connections I and II. A historical description of how and why these courses developed is presented in [1].

To be successful in today's world, one needs a comprehensive understanding of mathematics. Society needs individuals who have sound estimation skills, number and spatial sense, who are competent using and interpreting data, and who can use appropriate technology resources to solve problems and make informed decisions [3]. These skills are essential to becoming successful citizens, life-long learners, and competitive workers in a global market place [3].

Within the context of mathematics in every day life, students and teachers should continuously develop their ability to solve problems mathematically. Specifically, they should:

- Formulate and solve their own problems, develop and apply strategies to solve a wide variety of problems, and integrate mathematical reasoning, communication and connections (Nevada State Standard 6.0). 
- Investigate significant mathematical ideas and construct their own learning in all content areas in order to justify their thinking; reinforce and extend their logical reasoning abilities; reflect on and clarify their own thinking; and ask questions to extend their thinking (Nevada State Standard 8.0).

- View mathematics as an integrated whole, identifying relationships between context strands, and integrate mathematics with other disciplines, allowing the flexibility to approach problems in a variety of ways within and beyond the field of mathematics (Nevada State Standard 9.0).

This course has been developed specifically with the premise that all individuals must have an awareness of how mathematics fits into every day life. The content topics have arisen within the framework of the CCSD Power Standards (grades five through eight) and the Nevada State Standards.

\section{Spatial Relationships And Geometry}

Geometry, the study of space and spatial relationships, is present in the preparation of students across all grade levels. It has had a dominant role in the study of mathematics for centuries. Plato argued for the importance of geometry and mathematics as essential tools of life [4]. Geometry is fundamental because it is the basis for the physical world we live in, prepares students for the rigors of mathematical thinking, has a wealth of applications, and is a visual subject for which many students can relate [5].

This topic investigates geometric concepts in an exploratory fashion. Topics such as the Pythagorean Theorem, measurement, geometric shapes, and the coordinate axis will be explored to enhance understanding of not only the topics themselves, but also how to apply them to real world situations.

\section{Problem Solving, Reasoning And Mathematical Modeling}

A well-balanced mathematics curriculum consists of a mixture of concepts, contexts and skills. It is now recognized that the ability to use mathematics in problem solving is equally important as developing mathematical skills [6]. What is the point to having skills in mathematics if one fails to recognize how to apply them?

The ideas of problem solving and modeling are intertwined throughout this course. But for projects presented within this topic, students will use their investigative skills with concepts such as area, surface area, and volume.

\section{Financial And Economic Analysis}

Having a basic sense of economics prepares students to be better citizens and consumers. Financial and economic concepts are tools that individuals will use their entire lives. More than nine in ten adults and students believe that it is important for the people of the United States to have a good understanding of economics [7]. Secondary level instruction in economics influences students to develop positive attitudes about the economic system and the subject of economics [8]. Knowledge of economics and the ability to apply it to significant problems and issues are essential elements of responsible citizenship in a democratic society [9]. Citizens must be able to comprehend and use basic economic concepts in order to perform adequately as producers, consumers, investors, and voters in public elections [9].

This topic will use mathematical linear, exponential and log functions to analyze trends in economics and finance. Economic concepts such as CPI-U, inflation, gas prices, unemployment rates and the GDP will be explained, studied and analyzed in the context of the global market.

\section{Probability}

As society becomes more technologically advanced, the use of graphs to display data and probability to make predictions becomes more and more prevalent. Daily decision making and discussions of social issues are increasingly influenced by statistics and projected outcomes based on estimated probabilities [10]. To enhance 
students understanding of probability and statistics, research indicates that teachers must use real world examples and hands-on materials [11].

This topic will involve hands on activities with computer simulations in probability. Using these simulations, students will determine frequencies, and create frequency distributions and histograms.

\section{OVERVIEW OF PROJECTS}

Each of the projects outlined below are presented in full online [12] and solutions can be provided upon request. They have been developed within the context of the above topics, and address many of the state and district standards for school mathematics in grades five through eight (See Section C).

\section{Investigating The Pythagorean Theorem}

The purpose of this project is to use physical modeling to determine the validity of the Pythagorean Theorem.

This project consists of four parts: For Parts A and C students will be using a physical model, measuring lengths, and determining the area of figures to determine the validity of the Pythagorean Theorem (for those particular values). In Parts B and D they will generalize what has been found in previous parts for any values $a, b$ and $c$.

\section{Rope Stretching: Constructing Right Triangles (Inverse and Converse of the Pythagorean Theorem)}

The purpose of this project is to use rope stretching to show the construction of right triangles, thus providing examples that for lengths $a, b$ and $c$, if $a^{2}+b^{2}=c^{2}$ there is a right angle between sides $a$ and $b$. Also showing that if $a^{2}+b^{2} \neq c^{2}$, then the triangle with sides $a, b$ and $c$ is not a right triangle.

This project consists of four parts: For Parts A and B students will construct triangles with sides of various lengths, record the side lengths along with the degree measurements of the triangle, and identify and classify the triangles. Part $\mathrm{C}$ they will be demonstrating how their findings in A and B show the inverse (and converse) of the Pythagorean Theorem. For Part D they will demonstrate how to use the Pythagorean Theorem in current construction practices.

\section{Environmentally Conscious: Going from Grass to Desert Landscape}

Conservation of water is of particular environmental concern to the Las Vegas Valley. The purpose of this project is to determine the cost effectiveness of Xeriscape.

This project consists of four parts: For Part A, students will estimate the area of a lawn. For Part B they will determine the cost of changing to Xeriscape. For Parts C and D they will analyze the "break even" point, and decide based on analysis whether this is a worth while endeavor. 


\section{Project 1}

\section{Part A:}

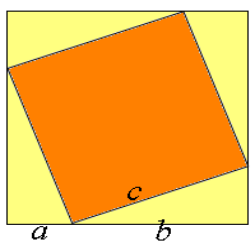

1. Cut out a square from construction paper (any size, but it would be to your advantage to make sure it's not too small).

2. Measure the sides, and determine the area. Record this on a separate sheet.

3. Draw a square inside this, where the corners touch each side as pictured above.

4. Measure and label all the sides of each "line."

5. Calculate and label the areas of each figure (4 triangles and 1 square).

6. Show how the values found in (5) sum to the value found in (2).

$\underline{\text { Part B: }}$

1. Cut out a square from construction paper.

2. Draw a square inside this, where the corners touch each side as pictured above.

3. Label the sides of the inside square as $c$.

4. The length of the larger square is bisected by the smaller one. Label these lengths as $a$ and $b$ so the length of one side of the larger square is $a+b$. Using symmetry, label legs of each triangle.

5. Calculate and label the areas of each figure (4 triangles and 1 square).

6. Using algebra, simply (5) to show that $a^{2}+b^{2}=c^{2}$.

Part C:

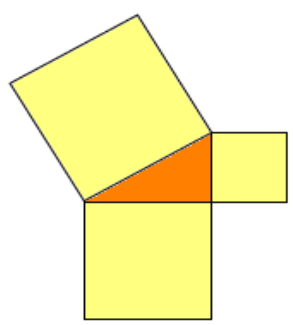

1. Using construction paper, cut out a right triangle.

2. Measure the lengths of each side of your triangle,

3. and make three squares whose side lengths are the same as the triangles sides (as pictured above).

4. Find the areas of each square, and record.

5. Show how the area of the larger square is related to the area of the two smaller squares.

$\underline{\text { Part D: }}$

1. Using construction paper, cut out a right triangle.

2. Label each side of your triangle $(a, b$ and $c)$, and make three squares whose side lengths are equal to the triangles sides (as pictured above).

3. Using scissors and cutting your smallest square into pieces, show how the two smaller squares cover the same area as the larger square.

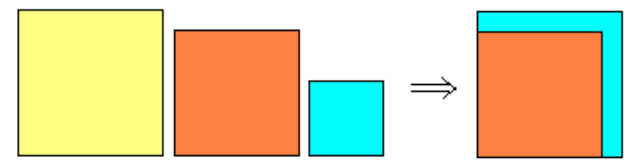

4. Convert this into a formula relating $a, b$ and $c$. 


\section{Project 2}

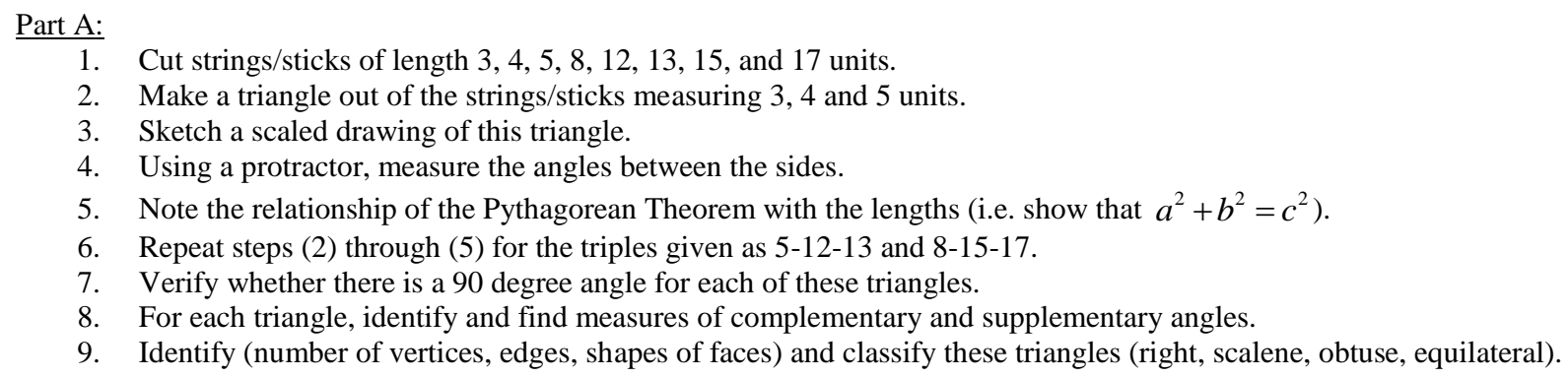

8. For each triangle, identify and find measures of complementary and supplementary angles.

9. Identify (number of vertices, edges, shapes of faces) and classify these triangles (right, scalene, obtuse, equilateral).

$\underline{\text { Part B: }}$

1. Make a triangle out of the strings/sticks of 3 different lengths that do not satisfy the Pythagorean Theorem (i.e. $\left.a^{2}+b^{2} \neq c^{2}\right)$.

2. Sketch a scaled drawing of this triangle.

3. Using a protractor, measure the angles between the sides.

4. Repeat steps (1) through (3) for at least two other triangles.

5. Is there a 90 degree angle for each of these triangles?

$\underline{\text { Part C: }}$

1. State the inverse of the Pythagorean Theorem.

2. Show how your examples support the Theorem, and the converse of the Theorem (recall the converse of $p \Rightarrow q$ is given by $\sim q \Rightarrow \sim p$ ).

Part D:

1. In construction, workers use the 3-4-5 relationship to square corners.

2. When they have an existing wall (in red) and they want to make a wall perpendicular to it (in blue), they measure 4 feet on the existing wall and make a mark. Then they measure a string that is 5 feet in length, and a chalk line string that is 3 feet in length. They stretch the 5 and 3 foot strings until they come together, and snap a chalk line.
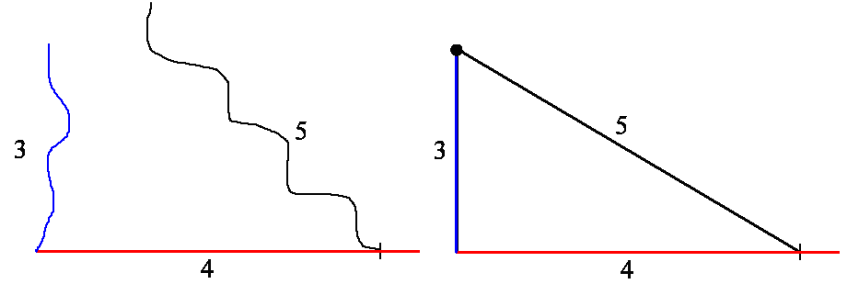

3. Explain how this makes a wall perpendicular to the original wall using the Pythagorean Theorem. 


\section{Project 3}

Xeriscape, pronounced zeer'-ih-scape, is a water-smart landscape that includes colorful flowers, plants and trees. You can earn $\$ 1$ per square foot rebate from the local water company for replacing your property's grass with a water-smart landscape. They estimate that you can save 55 gallons of water per square foot per year by replacing grass with a water-efficient landscape. (http://www.snwa.com/html/land xeri.html).

Your front yard is landscaped with grass according to the following schematic (dark circles are trees):

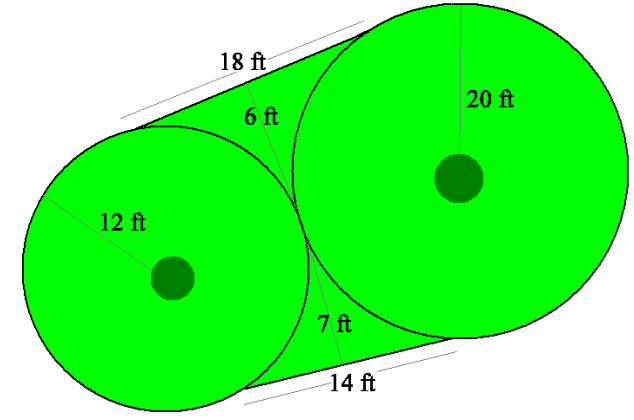

$\underline{\text { Part A: }}$

1. Estimate the area (square feet) of your front yard with the areas of the two circles, and the area of the two "triangle" connecting pieces.

2. Is this an over estimate, or an underestimate?

$\underline{\text { Part B: }}$

1. Determine how much it will cost to Xeriscape your lawn based on the following charges:

\begin{tabular}{|lll|}
\hline Removal of Grass: & $\$ 0.75$ & per square foot \\
\hline Purchase and Lay Weed Block & $\$ 0.50$ & per square foot \\
\hline Puchase and Add Drip Lines: & $\$ 20.00$ & per line \\
\hline Purchase and Plant Succulents: & $\$ 40.00$ & per plant \\
\hline Lay Rock Bed: & & \\
Materials & $\$ 6.00$ & per cubic yard \\
Labor & $\$ 0.50$ & per square foot \\
\hline
\end{tabular}

2. Here are some additional facts:

- You will not remove the trees, and they already have drip lines.

- Rocks should be laid at a depth of at least 3 inches to prevent weeds and erosion.

- You are considering adding 5 succulent plants. Include this as a separate cost item from the total.

3. In estimating the area, how do you decide how many digits to round?

\section{Part C:}

1. Determine the total rebate the water authority will give you ( $\$ 1$ per square foot).

2. Determine the yearly savings (you save 55 gallons of water per square foot per year at a charge of $\$ 1.38$ per 1000 gallons of water).

3. Make a linear function, with year along the horizontal $(x)$ and savings $(y)$ along the vertical based on (1) and (2).

4. Using a horizontal line for cost (without succulents), determine when you break even.

Part D:

1. What other considerations will you have in deciding whether this is a worthy endeavor?

2. Will you Xeriscape? Why or why not? 


\section{How Many M\&Ms in the Jar? An Exercise in Estimating, Volume and Problem Solving}

The purpose of this project is to use measuring to estimate the number of M\&M candies in different shaped containers. Students will be given a container filled with an unknown number of M\&M candies. They will estimate the number of candies in the container by using both counting and measuring techniques.

\section{Project 4}

Provide students with a formula sheet for unit conversion and computation of volumes.

Part A:

1. You will be given a rectangular shaped box full of M\&M's.

2. Determine the volume of the candy box.

3. Estimate the number of candies in the box using "counting."

a. Choose a unit of measuring volume (i.e. a cup, half-cup, etc.).

b. Determine how many M\&M's are in that unit of measurement.

c. Determine how many of your specified measurements from (a) are contained in the volume found in (2).

d. Estimate the number of candies in the box.

4. Determine the error in the above analysis.

a. Given the exact number of M\&M's in the box, by how many M\&M's are you off?

b. How many M\&M's is this per unit? In other words, how many M\&M's for each cup or half cup used in measurement?

c. With that error, how many M\&M's would you be off by if the box was tripled in size?

d. Find your percentage error. Recall percentage error is given by $\left|\frac{\text { exact - estimate }}{\text { exact }}\right| \times 100 \%$.

e. Is this value the same for (b) and (c)? Why or why not?

5. Estimate the number of candies in the box using "M\&M size."

a. Choose a unit of linear measurement (i.e. a inch, centimeter, etc).

b. Determine $M \& M$ volume by measuring and using the volume of ellipsoid formula.

c. Estimate the number of candies in the box.

6. Determine the error in the above analysis.

a. Given the exact number of M\&M's in the box, by how many M\&M's are you off?

b. If the box was tripled in size, and you had the same error, how many M\&M's would you be off by now?

c. Assuming the only "mistake" is determining the volume of the M\&M, what should the volume be in order to arrive at the correct answer?

d. What is the percentage error between M\&M volume in (5) and "actual" volume in (6)?

e. What is the most realistic choice for the dimensions of the M\&M to achieve the "correct" volume?

f. Comparing your measurements from (5) and the actual measurements from (6), what is the average you are off in your measurements?

Part B:

1. Repeat the procedure for Part A using a spherical shaped box full of M\&M's.

\section{Can I Get Sick? Exponential Growth of E-Coli Bacteria}

The purpose of this project is to identify the doubling time of the E-Coli bacteria, and to use this information to make a table of values. To calculate the equation for the number of cells present at any time, graph this equation and answer crucial questions about health.

Students will be provided a handout describing E-Coli [13] and how it behaves. They will then be provided with a scenario of exposure to E-Coli, and use both tables and graphs to answer questions about the number of cells, when you can get sick, and the effectiveness of current bacteria cleaning products. 


\section{Project 5}

Provide students with a description of E-Coli [13].

Part A:

1. Read the handout on E-Coli.

2. Answer the following questions:

a. How many cells does it take to make an individual sick?

b. What is the doubling time for E-Coli?

While cooking dinner at $8 p m$ you place uncooked chicken infected with $E$ coli on your counter. After removing the chicken to cook it, one cell remains.

Part B:

1. Starting with one cell at time 0 , make a table of values of the doubling times $(t)$ and the number of cells $Y(t)$ at that time.

2. Graph your data points.

3. At what time are there 64 cells?

4. Between what two times on your table are there first enough cells present to make you sick? What time of day is this?

Part C:

1. Find the exponential equation for the number of cells, $Y$, at any time, $t$. In general for doubling time $T$ and initial value $k, Y(t)=k\left(2^{1 / T}\right)^{t}$.

2. Incrementing $t$ in 5 minute intervals, graph $Y(t)$ for $t=0$ to 145 .

3. Using your graph to estimate, how long until enough cells are present to make someone sick?

4. If you don't clean it adequately, and leave it until just before bed to clean ( $4 \frac{1}{2}$ hours later), use the equation to determine how many cells are present.

5. If your cleaning product kills $99.9 \%$ of E coli bacteria cells and you clean at the time mentioned above, can you still get sick? How many cells would be left after cleaning?

\section{Can We All Fit? Modeling the Population Curve of the City of Las Vegas}

According to the U.S. Census for population growth in 1999 and 2000, Nevada was the fastest growing state, with an increase of $66.27 \%$. The population of Las Vegas went from about 140 thousand in 1960, to 1.4 million in 2000. Of particular concern to those of us residing in the city is how long this growth can continue. The purpose of this project is given population data for Clark County, Nevada, graph the data and find a suitable model to predict future growth.

Students will be given data for Clark County, Nevada from 1970 to 2004. They will analyze the percentage of Nevada residents that live in Clark County, and, graphing these values, will find the line through two data points. They will use this line to predict when Clark County may have up to $80 \%$ of the states population. In Part B they will determine the best equation to model the population data, and use it to predict future population. 


\section{Project 6}

\begin{tabular}{|c|c|c|c|c|c|c|}
\hline \multicolumn{7}{|c|}{$\begin{array}{l}\text { Here is data for the population of Clark County, and the state of Nevada } \\
\text { from } 1970 \text { to } 2004 \text { (taken from http://cber.unlv.edu/pop.html) }\end{array}$} \\
\hline & Year & $\begin{array}{l}\text { Clark Co } \\
\text { Popn }\end{array}$ & Nevada Popn. & Year & $\begin{array}{l}\text { Clark Co } \\
\text { Popn }\end{array}$ & Nevada Popn. \\
\hline & 1970 & 277,230 & 496,960 & 1989 & 708,750 & $1,162,340$ \\
\hline & 1971 & 293,000 & 521,971 & 1990 & 770,280 & $1,236,130$ \\
\hline & 1972 & 307,400 & 548,772 & 1991 & 835,080 & $1,318,597$ \\
\hline & 1973 & 319,400 & 571,173 & 1992 & 873,730 & $1,371,919$ \\
\hline & 1974 & 336,900 & 598,674 & 1993 & 916,837 & $1,431,956$ \\
\hline & 1975 & 351,300 & 621,975 & 1994 & 990,564 & $1,525,863$ \\
\hline & 1976 & 369,500 & 648,776 & 1995 & $1,055,435$ & $1,611,593$ \\
\hline & 1977 & 390,000 & 680,077 & 1996 & $1,119,052$ & $1,696,405$ \\
\hline & 1978 & 412,900 & 721,278 & 1997 & $1,193,388$ & $1,790,207$ \\
\hline & 1979 & 441,400 & 767,279 & 1998 & $1,261,150$ & $1,870,881$ \\
\hline & 1980 & 463,087 & 800,508 & 1999 & $1,327,145$ & $1,946,366$ \\
\hline & 1981 & 491,620 & 846,220 & 2000 & $1,394,440$ & $2,023,378$ \\
\hline & 1982 & 507,510 & 870,970 & 2001 & $1,485,855$ & $2,132,498$ \\
\hline & 1983 & 525,050 & 897,160 & 2002 & $1,549,657$ & $2,206,022$ \\
\hline & 1984 & 539,030 & 922,580 & 2003 & $1,620,748$ & $2,296,566$ \\
\hline & 1985 & 562,280 & 955,810 & 2004 & $1,715,337$ & $2,410,768$ \\
\hline & 1986 & 587,760 & 993,220 & & & \\
\hline & 1987 & 616,650 & $1,035,040$ & & & \\
\hline & 1988 & 661,690 & $1,096,130$ & & & \\
\hline \multicolumn{7}{|l|}{ Part A: } \\
\hline$\overline{1 .}$ & \multicolumn{6}{|c|}{ Let's analyze the population of Clark County in relation to the State. } \\
\hline 2. & \multicolumn{6}{|c|}{ Using a table, find the percentage of the states population residing in Clark County for each year. } \\
\hline 3. & \multicolumn{6}{|c|}{ What is the average percent of the Nevada population residing in Clark Co. from 1970 to $2004 ?$} \\
\hline 4. & \multicolumn{6}{|c|}{$\begin{array}{l}\text { Make a graph of these values. Specifically, put the Year along the horizontal and the Percentage of Population along } \\
\text { the vertical. }\end{array}$} \\
\hline 5. & \multicolumn{6}{|c|}{ Find the equation of the line through the points for years 1990 and 2004.} \\
\hline 6. & \multicolumn{6}{|c|}{ What does the slope of this line tell you about the changing dynamics of population in the state of Nevada? } \\
\hline 7. & \multicolumn{6}{|c|}{$\begin{array}{l}\text { Using your line as a predictor, what year will the state have } 80 \% \text { of its population in Clark County? Is this feasible, } \\
\text { why or why not? }\end{array}$} \\
\hline \multicolumn{7}{|l|}{ Part B: } \\
\hline 1. & \multicolumn{6}{|c|}{ Now let's analyze the population growth of Clark County using a table. } \\
\hline 2. & \multicolumn{6}{|c|}{ Find the population difference per year. } \\
\hline 3. & \multicolumn{6}{|c|}{ Find the average difference per month. } \\
\hline 4. & \multicolumn{6}{|c|}{ Find the percentage change of population per year. Recall that percentage change is found by $\frac{\text { new }- \text { old }}{\text { old }} \times 100 \%$. } \\
\hline 5. & \multicolumn{6}{|c|}{ What year(s) do we find the largest percentage increase of population? } \\
\hline 6. & \multicolumn{6}{|c|}{$\begin{array}{l}\text { Of the values found above, the most consistent value is given in (4). Explain why this may be true from both a } \\
\text { mathematical and sociological viewpoint. }\end{array}$} \\
\hline 7. & \multicolumn{6}{|c|}{$\begin{array}{l}\text { Find the average of the values in (4). Make a prediction of growth, beginning with } 277,230 \text { people in } 1970 \text { and } \\
\text { growing at the average percentage rate. }\end{array}$} \\
\hline 8. & \multicolumn{6}{|c|}{ Graph the data along with your estimate. } \\
\hline 9. & \multicolumn{6}{|c|}{ Does your graph over or underestimate the actual values? } \\
\hline 10. & \multicolumn{6}{|c|}{$\begin{array}{l}\text { It appears the data fits very well in the beginning, and then at the "tail" end doesn't do as well. Ignoring the data } \\
\text { before } 1988 \text {, find the value of percentage change that best seems to fit the data. }\end{array}$} \\
\hline 11. & \multicolumn{6}{|c|}{$\begin{array}{l}\text { before 1988, find the value of percentage change that best seems to fit the data. } \\
\text { Using the equation from (10) as a predictor, determine what year we "should" break a population of } 2 \text { million. }\end{array}$} \\
\hline
\end{tabular}




\section{Show Me the Money: Investments and Earning Analysis}

The purpose of this project is to investigate the impact of changing values of initial investment, and length of investment on money earned.

This project consists of three parts: For Part A, students will determine the quick growth of an exponential equation when the base value is large. For Parts B and C they will investigate the effect of investing at a certain percentage for periods of time.

\section{Project 7}

$\underline{\text { Part A: }}$

You are given a choice. After one month (31 days) you can have either \$1 million, or you can start with $\$ 0.01$ on Day 0 and double your money every day for those 31 days.

1. Make a table of values similar to below up to 31 days.

\begin{tabular}{c|c|c} 
Day & Cents & Dollars \\
\hline 0 & 1 & 0.01 \\
\hline & &
\end{tabular}

2. According to your table, how much money will you have after 31 days if you choose to "double your money"?

3. Which would you choose, and why?

4. According to your chart, between what two days do you "crack" a million dollars?

5. Graph the equation, with day along the horizontal and dollars along the vertical. On the same plot graph the horizontal line at $\$ 2,000,000$.

6. Using your graph, between what days do you "crack" a million dollars?

7. Find the exponential equation that represents this word problem.

$\underline{\text { Part B: }}$

$$
\begin{aligned}
& \text { When investing, you discover you can at most earn } 6 \% \text { per year. } \\
& \text { You are now 35, and want to retire with \$1million at age } 65 .
\end{aligned}
$$

1. You have an initial investment of $\$ 20,000$. You make no additional deposits and withdraws. Make a table of values similar to below up to year 30 (age 65).

\begin{tabular}{c|c|c} 
Year & Age & Amount \\
\hline 0 & 35 & $20,000.00$ \\
\hline 1 & 36 & $21,200.00$ \\
\hline & &
\end{tabular}

2. According to your table, how much money will you have at age 65 ?

3. Well, obviously you are going to have to deposit some money regularly to have that $\$ 1$ million. Make another table of values, and add in a yearly deposit amount, $A$. Find the value of $A$ you will need to invest (rounded to the nearest $\$ 100$ ) to have $\$ 1$ million by age 65 .

4. What is the total amount you are investing in addition to the initial investment of $\$ 20,000$ over the 30 year period?

Part C:

$$
\begin{aligned}
& \text { This is why "they" say to start investing early. Again, you discover you can at most } \\
& \text { earn } 6 \% \text { per year. You are now 25, and want to retire with \$1million at age } 65 .
\end{aligned}
$$

1. You have an initial investment of $\$ 20,000$. You make no additional deposits and withdraws. Make a table of values similar to below up to year 40 (age 65).

\begin{tabular}{c|c|c} 
Year & Age & Amount \\
\hline 0 & 35 & $20,000.00$ \\
\hline 1 & 36 & $21,200.00$ \\
\hline & &
\end{tabular}

2. According to your table, how much money will you have at age 65 ?

3. How much more do you have after 40 years in comparing to Part B, when you only have 30 years to invest? 
4. Again, you are going to have to deposit some money regularly to have that $\$ 1$ million. Make another table of values, and add in a yearly deposit amount, $A$. Find the value of $A$ you will need to invest (rounded to the nearest $\$ 100$ ) to have $\$ 1$ million by age 65 .

5. Compare the above value to the value found in Part B. How much less (as a percentage) is the yearly investment value when you invest for the extra 10 years?

6. What is the total amount you are investing in addition to the initial investment of $\$ 20,000$ over the 30 year period?

7. Compare the above value to the value found in Part B. How much less (as a percentage) is the total investment value when you invest for the extra 10 years?

\title{
Understanding Economics: CPI-U, Inflation, Gas Prices, Unemployment and GDP
}

The purpose of this project is to use mathematics to analyze basic economic principles.

This project consists of five parts: For Parts A, B and C students will be looking at the Consumer Price Index and Inflation. For Part D they will be analyzing the price of gas (crude oil) over the years. For Part E they will be analyzing the Unemployment Rate trends over the years. And for Part F they will be analyzing the Gross Domestic Product and National Income.

\section{Project 8}

Provide students with a blank excel sheet [14] which contains the data mentioned throughout this lab.

$\underline{\text { Part A: }}$

\author{
The Consumer Price Index (CPI-U) is compiled by the Bureau of Labor \\ Statistics and is based upon a 1982 Base of 100. A Consumer \\ Price Index of 158 indicates 58\% inflation since 1982.
}

1. The following set of data is provided on the CPI-U each month for the years 1970 through 2005 .

\begin{tabular}{|c|c|c|c|c|c|c|c|c|c|c|c|c|}
\hline Year & Jan & Feb & Mar & April & May & June & July & Aug & Sept & Oct & Nov & Dec \\
\hline 1970 & 37.8 & 38 & 38.2 & 38.5 & 38.6 & 38.8 & 39 & 39 & 39.2 & 39.4 & 39.6 & 39.8 \\
\hline 1971 & 39.8 & 39.9 & 40 & 40.1 & 40.3 & 40.6 & 40.7 & 40.8 & 40.8 & 40.9 & 40.9 & 41.1 \\
\hline 1972 & 41.1 & 41.3 & 41.4 & 41.5 & 41.6 & 41.7 & 41.9 & 42 & 42.1 & 42.3 & 42.4 & 42.5 \\
\hline 1973 & 42.6 & 42.9 & 43.3 & 43.6 & 43.9 & 44.2 & 44.3 & 45.1 & 45.2 & 45.6 & 45.9 & 46.2 \\
\hline 1974 & 46.6 & 47.2 & 47.8 & 48 & 48.6 & 49 & 49.4 & 50 & 50.6 & 51.1 & 51.5 & 51.9 \\
\hline 1975 & 52.1 & 52.5 & 52.7 & 52.9 & 53.2 & 53.6 & 54.2 & 54.3 & 54.6 & 54.9 & 55.3 & 55.5 \\
\hline 1976 & 55.6 & 55.8 & 55.9 & 56.1 & 56.5 & 56.8 & 57.1 & 57.4 & 57.6 & 57.9 & 58 & 58.2 \\
\hline 1977 & 58.5 & 59.1 & 59.5 & 60 & 60.3 & 60.7 & 61 & 61.2 & 61.4 & 61.6 & 61.9 & 62.1 \\
\hline 1978 & 62.5 & 62.9 & 63.4 & 63.9 & 64.5 & 65.2 & 65.7 & 66 & 66.5 & 67.1 & 67.4 & 67.7 \\
\hline 1979 & 68.3 & 69.1 & 69.8 & 70.6 & 71.5 & 72.3 & 73.1 & 73.8 & 74.6 & 75.2 & 75.9 & 76.7 \\
\hline 1980 & 77.8 & 78.9 & 80.1 & 81 & 81.8 & 82.7 & 82.7 & 83.3 & 84 & 84.8 & 85.5 & 86.3 \\
\hline 1981 & 87 & 87.9 & 88.5 & 89.1 & 89.8 & 90.6 & 91.6 & 92.3 & 93.2 & 93.4 & 93.7 & 94 \\
\hline 1982 & 94.3 & 94.6 & 94.5 & 94.9 & 95.8 & 97 & 97.5 & 97.7 & 97.9 & 98.2 & 98 & 97.6 \\
\hline 1983 & 97.8 & 97.9 & 97.9 & 98.6 & 99.2 & 99.5 & 99.9 & 100.2 & 100.7 & 101 & 101.2 & 101.3 \\
\hline 1984 & 101.9 & 102.4 & 102.6 & 103.1 & 103.4 & 103.7 & 104.1 & 104.5 & 105 & 105.3 & 105.3 & 105.3 \\
\hline 1985 & 105.5 & 106 & 106.4 & 106.9 & 107.3 & 107.6 & 107.8 & 108 & 108.3 & 108.7 & 109 & 109.3 \\
\hline 1986 & 109.6 & 109.3 & 108.8 & 108.6 & 108.9 & 109.5 & 109.5 & 109.7 & 110.2 & 110.3 & 110.4 & 110.5 \\
\hline 1987 & 111.2 & 111.6 & 112.1 & 112.7 & 113.1 & 113.5 & 113.8 & 114.4 & 115 & 115.3 & 115.4 & 115.4 \\
\hline 1988 & 115.7 & 116 & 116.5 & 117.1 & 117.5 & 118 & 118.5 & 119 & 119.8 & 120.2 & 120.3 & 120.5 \\
\hline 1989 & 121.1 & 121.6 & 122.3 & 123.1 & 123.8 & 124.1 & 124.4 & 124.6 & 125 & 125.6 & 125.9 & 126.1 \\
\hline 1990 & 127.4 & 128 & 128.7 & 128.9 & 129.2 & 129.9 & 130.4 & 131.6 & 132.7 & 133.5 & 133.8 & 133.8 \\
\hline 1991 & 134.6 & 134.8 & 135 & 135.2 & 135.6 & 136 & 136.2 & 136.6 & 137.2 & 137.4 & 137.8 & 137.9 \\
\hline 1992 & 138.1 & 138.6 & 139.3 & 139.5 & 139.7 & 140.2 & 140.5 & 140.9 & 141.3 & 141.8 & 142 & 141.9 \\
\hline 1993 & 142.6 & 143.1 & 143.6 & 144 & 144.2 & 144.4 & 144.4 & 144.8 & 145.1 & 145.7 & 145.8 & 145.8 \\
\hline 1994 & 146.2 & 146.7 & 147.2 & 147.4 & 147.5 & 148 & 148.4 & 149 & 149.4 & 149.5 & 149.7 & 149.7 \\
\hline 1995 & 150.3 & 150.9 & 151.4 & 151.9 & 152.2 & 152.5 & 152.5 & 152.9 & 153.2 & 153.7 & 153.6 & 153.5 \\
\hline 1996 & 154.4 & 154.9 & 155.7 & 156.3 & 156.6 & 156.7 & 157 & 157.3 & 157.8 & 158.3 & 158.6 & 158.6 \\
\hline 1997 & 159.1 & 159.6 & 160 & 160.2 & 160.1 & 160.3 & 160.5 & 160.8 & 161.2 & 161.6 & 161.5 & 161.3 \\
\hline 1998 & 161.6 & 161.9 & 162.2 & 162.5 & 162.8 & 163 & 163.2 & 163.4 & 163.6 & 164 & 164 & 163.9 \\
\hline 1999 & 164.3 & 164.5 & 165 & 166.2 & 166.2 & 166.2 & 166.7 & 167.1 & 167.9 & 168.2 & 168.3 & 168.3 \\
\hline 2000 & 168.8 & 169.8 & 171.2 & 171.3 & 171.5 & 172.4 & 172.8 & 172.8 & 173.7 & 174 & 174.1 & 174 \\
\hline 2001 & 175.1 & 175.8 & 176.2 & 176.9 & 177.7 & 178 & 177.5 & 177.5 & 178.3 & 177.7 & 177.4 & 176.7 \\
\hline 2002 & 177.1 & 177.8 & 178.8 & 179.8 & 179.8 & 179.9 & 180.1 & 180.7 & 181 & 181.3 & 181.3 & 180.9 \\
\hline 2003 & 181.7 & 183.1 & 184.2 & 183.8 & 183.5 & 183.7 & 183.9 & 184.6 & 185.2 & 185 & 184.5 & 184.3 \\
\hline 2004 & 185.2 & 186.2 & 187.4 & 188 & 189.1 & 189.7 & 189.4 & 189.5 & 189.9 & 190.9 & 191 & 190.3 \\
\hline 2005 & 190.7 & 191.8 & 193.3 & 194.6 & 194.4 & 194.5 & 195.4 & 196.4 & & & & \\
\hline
\end{tabular}


2. Find the average CPI-U for each year. This is typically called the Annual CPI-U.

3. Find the percent change in the Annual CPI-U from year to year.

4. This percent change is what is commonly known as Inflation.

5. The following data is provided on Inflation rates for each month from 1970 to 2005 .

\begin{tabular}{|c|c|c|c|c|c|c|c|c|c|c|c|c|}
\hline Year & Jan & Feb & Mar & April & May & June & July & Aug & Sept & Oct & Nov & Dec \\
\hline 1970 & $6.18 \%$ & $6.15 \%$ & $5.82 \%$ & $6.06 \%$ & $6.04 \%$ & $6.01 \%$ & $5.98 \%$ & $5.41 \%$ & $5.66 \%$ & $5.63 \%$ & $5.60 \%$ & $5.57 \%$ \\
\hline 1971 & $5.29 \%$ & $5.00 \%$ & $4.71 \%$ & $4.16 \%$ & $4.40 \%$ & $4.64 \%$ & $4.36 \%$ & $4.62 \%$ & $4.08 \%$ & $3.81 \%$ & $3.28 \%$ & $3.27 \%$ \\
\hline 1972 & $3.27 \%$ & $3.51 \%$ & $3.50 \%$ & $3.49 \%$ & $3.23 \%$ & $2.71 \%$ & $2.95 \%$ & $2.94 \%$ & $3.19 \%$ & $3.42 \%$ & $3.67 \%$ & $3.41 \%$ \\
\hline 1973 & $3.65 \%$ & $3.87 \%$ & $4.59 \%$ & $5.06 \%$ & $5.53 \%$ & $6.00 \%$ & $5.73 \%$ & $7.38 \%$ & $7.36 \%$ & $7.80 \%$ & $8.25 \%$ & $8.71 \%$ \\
\hline 1974 & $9.39 \%$ & $10.02 \%$ & $10.39 \%$ & $10.09 \%$ & $10.71 \%$ & $10.86 \%$ & $11.51 \%$ & $10.86 \%$ & $11.95 \%$ & $12.06 \%$ & $12.20 \%$ & $12.34 \%$ \\
\hline 1975 & $11.80 \%$ & $11.23 \%$ & $10.25 \%$ & $10.21 \%$ & $9.47 \%$ & $9.39 \%$ & $9.72 \%$ & $8.60 \%$ & $7.91 \%$ & $7.44 \%$ & $7.38 \%$ & $6.94 \%$ \\
\hline 1976 & $6.72 \%$ & $6.29 \%$ & $6.07 \%$ & $6.05 \%$ & $6.20 \%$ & $5.97 \%$ & $5.35 \%$ & $5.71 \%$ & $5.49 \%$ & $5.46 \%$ & $4.88 \%$ & $4.86 \%$ \\
\hline 1977 & $5.22 \%$ & $5.91 \%$ & $6.44 \%$ & $6.95 \%$ & $6.73 \%$ & $6.87 \%$ & $6.83 \%$ & $6.62 \%$ & $6.60 \%$ & $6.39 \%$ & $6.72 \%$ & $6.70 \%$ \\
\hline 1978 & $6.84 \%$ & $6.43 \%$ & $6.55 \%$ & $6.50 \%$ & $6.97 \%$ & $7.41 \%$ & $7.70 \%$ & $7.84 \%$ & $8.31 \%$ & $8.93 \%$ & $8.89 \%$ & $9.02 \%$ \\
\hline 1979 & $9.28 \%$ & $9.86 \%$ & $10.09 \%$ & $10.49 \%$ & $10.85 \%$ & $10.89 \%$ & $11.26 \%$ & $11.82 \%$ & $12.18 \%$ & $12.07 \%$ & $12.61 \%$ & $13.29 \%$ \\
\hline 1980 & $13.91 \%$ & $14.18 \%$ & $14.76 \%$ & $14.73 \%$ & $14.41 \%$ & $14.38 \%$ & $13.13 \%$ & $12.87 \%$ & $12.60 \%$ & $12.77 \%$ & $12.65 \%$ & $12.52 \%$ \\
\hline 1981 & $11.83 \%$ & $11.41 \%$ & $10.49 \%$ & $10.00 \%$ & $9.78 \%$ & $9.55 \%$ & $10.76 \%$ & $10.80 \%$ & $10.95 \%$ & $10.14 \%$ & $9.59 \%$ & $8.92 \%$ \\
\hline 1982 & $8.39 \%$ & $7.62 \%$ & $6.78 \%$ & $6.51 \%$ & $6.68 \%$ & $7.06 \%$ & $6.44 \%$ & $5.85 \%$ & $5.04 \%$ & $5.14 \%$ & $4.59 \%$ & $3.83 \%$ \\
\hline 1983 & $3.71 \%$ & $3.49 \%$ & $3.60 \%$ & $3.90 \%$ & $3.55 \%$ & $2.58 \%$ & $2.46 \%$ & $2.56 \%$ & $2.86 \%$ & $2.85 \%$ & $3.27 \%$ & $3.79 \%$ \\
\hline 1984 & $4.19 \%$ & $4.60 \%$ & $4.80 \%$ & $4.56 \%$ & $4.23 \%$ & $4.22 \%$ & $4.20 \%$ & $4.29 \%$ & $4.27 \%$ & $4.26 \%$ & $4.05 \%$ & $3.95 \%$ \\
\hline 1985 & $3.53 \%$ & $3.52 \%$ & $3.70 \%$ & $3.69 \%$ & $3.77 \%$ & $3.76 \%$ & $3.55 \%$ & $3.35 \%$ & $3.14 \%$ & $3.23 \%$ & $3.51 \%$ & $3.80 \%$ \\
\hline 1986 & $3.89 \%$ & $3.11 \%$ & $2.26 \%$ & $1.59 \%$ & $1.49 \%$ & $1.77 \%$ & $1.58 \%$ & $1.57 \%$ & $1.75 \%$ & $1.47 \%$ & $1.28 \%$ & $1.10 \%$ \\
\hline 1987 & $1.46 \%$ & $2.10 \%$ & $3.03 \%$ & $3.78 \%$ & $3.86 \%$ & $3.65 \%$ & $3.93 \%$ & $4.28 \%$ & $4.36 \%$ & $4.53 \%$ & $4.53 \%$ & $4.43 \%$ \\
\hline 1988 & $4.05 \%$ & $3.94 \%$ & $3.93 \%$ & $3.90 \%$ & $3.89 \%$ & $3.96 \%$ & $4.13 \%$ & $4.02 \%$ & $4.17 \%$ & $4.25 \%$ & $4.25 \%$ & $4.42 \%$ \\
\hline 1989 & $4.67 \%$ & $4.83 \%$ & $4.98 \%$ & $5.12 \%$ & $5.36 \%$ & $5.17 \%$ & $4.98 \%$ & $4.71 \%$ & $4.34 \%$ & $4.49 \%$ & $4.66 \%$ & $4.65 \%$ \\
\hline 1990 & $5.20 \%$ & $5.26 \%$ & $5.23 \%$ & $4.71 \%$ & $4.36 \%$ & $4.67 \%$ & $4.82 \%$ & $5.62 \%$ & $6.16 \%$ & $6.29 \%$ & $6.27 \%$ & $6.11 \%$ \\
\hline 1991 & $5.65 \%$ & $5.31 \%$ & $4.90 \%$ & $4.89 \%$ & $4.95 \%$ & $4.70 \%$ & $4.45 \%$ & $3.80 \%$ & $3.39 \%$ & $2.92 \%$ & $2.99 \%$ & $3.06 \%$ \\
\hline 1992 & $2.60 \%$ & $2.82 \%$ & $3.19 \%$ & $3.18 \%$ & $3.02 \%$ & $3.09 \%$ & $3.16 \%$ & $3.15 \%$ & $2.99 \%$ & $3.20 \%$ & $3.05 \%$ & $2.90 \%$ \\
\hline 1993 & $3.26 \%$ & $3.25 \%$ & $3.09 \%$ & $3.23 \%$ & $3.22 \%$ & $3.00 \%$ & $2.78 \%$ & $2.77 \%$ & $2.69 \%$ & $2.75 \%$ & $2.68 \%$ & $2.75 \%$ \\
\hline 1994 & $2.52 \%$ & $2.52 \%$ & $2.51 \%$ & $2.36 \%$ & $2.29 \%$ & $2.49 \%$ & $2.77 \%$ & $2.90 \%$ & $2.96 \%$ & $2.61 \%$ & $2.67 \%$ & $2.67 \%$ \\
\hline 1995 & $2.80 \%$ & $2.86 \%$ & $2.85 \%$ & $3.05 \%$ & $3.19 \%$ & $3.04 \%$ & $2.76 \%$ & $2.62 \%$ & $2.54 \%$ & $2.81 \%$ & $2.61 \%$ & $2.54 \%$ \\
\hline 1996 & $2.73 \%$ & $2.65 \%$ & $2.84 \%$ & $2.90 \%$ & $2.89 \%$ & $2.75 \%$ & $2.95 \%$ & $2.88 \%$ & $3.00 \%$ & $2.99 \%$ & $3.26 \%$ & $3.32 \%$ \\
\hline 1997 & $3.04 \%$ & $3.03 \%$ & $2.76 \%$ & $2.50 \%$ & $2.23 \%$ & $2.30 \%$ & $2.23 \%$ & $2.23 \%$ & $2.15 \%$ & $2.08 \%$ & $1.83 \%$ & $1.70 \%$ \\
\hline 1998 & $1.57 \%$ & $1.44 \%$ & $1.37 \%$ & $1.44 \%$ & $1.69 \%$ & $1.68 \%$ & $1.68 \%$ & $1.62 \%$ & $1.49 \%$ & $1.49 \%$ & $1.55 \%$ & $1.61 \%$ \\
\hline 1999 & $1.67 \%$ & $1.61 \%$ & $1.73 \%$ & $2.28 \%$ & $2.09 \%$ & $1.96 \%$ & $2.14 \%$ & $2.26 \%$ & $2.63 \%$ & $2.56 \%$ & $2.62 \%$ & $2.68 \%$ \\
\hline 2000 & $2.74 \%$ & $3.22 \%$ & $3.76 \%$ & $3.07 \%$ & $3.19 \%$ & $3.73 \%$ & $3.66 \%$ & $3.41 \%$ & $3.45 \%$ & $3.45 \%$ & $3.45 \%$ & $3.39 \%$ \\
\hline 2001 & $3.73 \%$ & $3.53 \%$ & $2.92 \%$ & $3.27 \%$ & $3.62 \%$ & $3.25 \%$ & $2.72 \%$ & $2.72 \%$ & $2.65 \%$ & $2.13 \%$ & $1.90 \%$ & $1.55 \%$ \\
\hline 2002 & $1.14 \%$ & $1.14 \%$ & $1.48 \%$ & $1.64 \%$ & $1.18 \%$ & $1.07 \%$ & $1.46 \%$ & $1.80 \%$ & $1.51 \%$ & $2.03 \%$ & $2.20 \%$ & $2.38 \%$ \\
\hline 2003 & $2.60 \%$ & $2.98 \%$ & $3.02 \%$ & $2.22 \%$ & $2.06 \%$ & $2.11 \%$ & $2.11 \%$ & $2.16 \%$ & $2.32 \%$ & $2.04 \%$ & $1.77 \%$ & $1.88 \%$ \\
\hline 2004 & $1.93 \%$ & $1.69 \%$ & $1.74 \%$ & $2.29 \%$ & $3.05 \%$ & $3.27 \%$ & $2.99 \%$ & $2.65 \%$ & $2.54 \%$ & $3.19 \%$ & $3.52 \%$ & $3.26 \%$ \\
\hline 2005 & $2.97 \%$ & $3.01 \%$ & $3.15 \%$ & $3.51 \%$ & $2.80 \%$ & $2.53 \%$ & $3.17 \%$ & $3.64 \%$ & & & & \\
\hline
\end{tabular}

6. Find the average inflation for each year.

7. Compare the values from (3) and (6). Do they agree?

8. Graph Inflation vs. Time, and investigate the graph. What years do you see the largest "spikes" in Inflation? What social/political factors could have influenced these trends? Mention at least one other thing you notice about this graph.

$\underline{\text { Part B: }}$

1. You can calculate the inflation rate between any two specific dates.

2. For example, between January 1970 and December 1984, the CPI-U went from 37.8 to 105.3, indicating an inflation rate change of $\frac{105.3-37.4}{37.4} \times 100=178.57 \%$.

3. In fact, there is an "online calculator" for this exercise found at the link below.

\begin{tabular}{|c|c|c|}
\hline & Month & Year \\
\hline Start Date: & January & 2005 \\
\hline End Date: & January & 2005 \\
\hline & \multicolumn{2}{|c|}{ Calculate Inflation Rate } \\
\hline $\begin{array}{r}\text { The inflation rate from January } 1970 \\
\text { to December } 1984 \text { is }\end{array}$ & \multicolumn{2}{|c|}{$178.57 \%$} \\
\hline
\end{tabular}

4. Calculate the inflation rate between your birth year and today. Use the online calculator to verify your results.

Part C:

1. The CPI-U also can tell us how much something would have cost us "back then" in today's dollars.

2. To do this we divide the "current" Annual CPI-U by the "then" Annual CPI-U.

3. Make a table of three columns. The first column will be the year (1970 through 2005). The second will have the Annual CPI-U for that particular year (you found this in Part A). In the last column, use the CPI-U Annual value for 2005 (193.8875) to calculate "Today's Dollars" value. 
$\underline{\text { Part D: }}$

1. Now we will investigate the price of gas since 1970. The table below contains data on the US annual average crude oil price in dollars (\$) per barrel of oil (bbl) from 1970 to 2005.

\begin{tabular}{|c|c|c|c|}
\hline \multicolumn{4}{|c|}{ US Average (\$/bbl) } \\
\hline Year & $\begin{array}{c}\text { Average } \\
\text { Nominal } \\
\end{array}$ & Year & $\begin{array}{l}\text { Average } \\
\text { Nominal } \\
\end{array}$ \\
\hline 1970 & 3.39 & 1988 & 14.87 \\
\hline 1971 & 3.6 & 1989 & 18.33 \\
\hline 1972 & 3.6 & 1990 & 23.19 \\
\hline 1973 & 4.75 & 1991 & 20.2 \\
\hline 1974 & 9.35 & 1992 & 19.25 \\
\hline 1975 & 7.67 & 1993 & 16.75 \\
\hline 1976 & 13.1 & 1994 & 15.66 \\
\hline 1977 & 14.4 & 1995 & 16.75 \\
\hline 1978 & 14.95 & 1996 & 20.46 \\
\hline 1979 & 25.1 & 1997 & 18.64 \\
\hline 1980 & 37.42 & 1998 & 11.91 \\
\hline 1981 & 35.75 & 1999 & 16.56 \\
\hline 1982 & 31.83 & 2000 & 27.39 \\
\hline 1983 & 29.08 & 2001 & 23 \\
\hline 1984 & 28.75 & 2002 & 22.81 \\
\hline 1985 & 26.92 & 2003 & 27.69 \\
\hline 1986 & 14.44 & 2004 & 37.66 \\
\hline 1987 & 17.75 & 2005 & 46.47 \\
\hline
\end{tabular}

2. Graph this data, with year along the horizontal and average price per barrel along the vertical.

3. What does this graph tell you about the price of gas today compared to all the years previous? Is there any problem with the design of our analysis?

4. So (hopefully) we discovered that we did not take into account that our dollar value is different today than previous years. Let's add another column of data, which is a "corrected" dollar value based on what the dollar is using the 2005 Annual CPI-U.

5. To find the adjusted price per barrel, multiply the price per barrel by the "Today Dollar Value" you found in Part C for each year.

\begin{tabular}{|c|c|c|}
\hline \multicolumn{3}{|c|}{ US Average (\$/bbl) } \\
\hline Year & $\begin{array}{l}\text { Average } \\
\text { Nominal }\end{array}$ & Guess Adjusted \\
\hline 1970 & 3.39 & $=4.99(3.39)=16.93$ \\
\hline 1971 & 3.6 & \\
\hline
\end{tabular}

6. Graph your results. Does this change your perspective on gas prices? When was it worst?

$\underline{\text { Part E: }}$

The Unemployment Rate is the number of unemployed individuals expressed as a percentage of the labor force.

1. For the City of Las Vegas and surrounding areas, the following data is given on number of "workable" persons employed and not employed.

\begin{tabular}{c|cc} 
Year & Employed & $\begin{array}{c}\text { Not } \\
\text { Employed }\end{array}$ \\
\hline 1990 & 387880.8 & 19881.9 \\
1991 & 409424.8 & 28207.0 \\
1992 & 426767.8 & 31816.8 \\
1993 & 454787.3 & 32995.3 \\
1994 & 497080.6 & 32319.3 \\
1995 & 527087.2 & 31084.1 \\
1996 & 562980.8 & 30054.6 \\
1997 & 602494.4 & 27840.1 \\
1998 & 637979.8 & 28425.6 \\
1999 & 675963.3 & 29780.9 \\
2000 & 694465.2 & 33821.7 \\
2001 & 718294.9 & 41670.0 \\
2002 & 733562.0 & 45101.1 \\
2003 & 759808.4 & 41963.8 \\
2004 & 791773.8 & 36184.4 \\
2005 & 823081.1 & 34094.1
\end{tabular}

2. Notice that we only have data from 1990 to 2005 . These values are calculated as averages over each month in the given year (which is why they are not whole numbers, because we know that there is no such thing as 0.8 of a person).

3. From this, we can calculate the Work Force (the total number of people able to work) and the Unemployment Rate (number of unemployed persons divided by the work force).

4. Make a table with these values. 


\section{Birthdays and the Roll of Dice}

The purpose of this project is to become more familiar with exercises in probability, frequency distributions, etc.

This project consists of two parts: For Part A, students will be analyzing the "Birthday" problem, which is the likelihood of random people sharing a birthday. For Part B they will be generating random numbers (with sixsided number cubes or software) to determine the likelihood of a particular "Roll." They will be creating a frequency distribution of both the actual and predicted outcomes for these events.

\section{Project 9}

\section{Part A: \\ 1. For two people, $A$ and $B$, what is the probability they will have different birthdays? \\ 2. What is the probability they will have the same birthday (neglect leap year)? \\ 3. If another person comes along, what is the probability they will all have different birthdays? \\ 4. What is the probability one of the two in the previous question will share a birthday? \\ 5. Make a table of values, starting from $n=2$ to 4 . This represents the number of people in your group. Fill in the table accordingly...

\begin{tabular}{|c|c|c|c|c|c|c|}
\hline $\mathbf{n}$ & \begin{tabular}{|c} 
Possible \\
Different Days
\end{tabular} & & $\begin{array}{c}\text { Days per } \\
\text { Year }\end{array}$ & $\begin{array}{c}\text { Prob. Of } \\
\text { Event }\end{array}$ & Combined & 1 - Prob. \\
\hline 2 & 364 & out of & 365 & $=0.99726$ & & $0.3 \%$ \\
\hline 3 & 363 & & 365 & 0.994521 & 0.99179583 & $0.8 \%$ \\
\hline 4 & 362 & & 365 & 0.991781 & 0.98364409 & $1.6 \%$ \\
\hline
\end{tabular} \\ "Possible Different Days" represents the number of days in the year possible for the new person to not share a birthday with the others. For example, in a group of two, the only way they share a birthday is if it falls on the same day, so there are 364 possible days for them to have a different birthday. \\ "Probability of Event" is found by dividing "Possible Days" by "Days per year" \\ "Combined" represents a running tally so to speak, of the probability of these mutually exclusive events. In other words a product of all probabilities up to this point. \\ "1-Prob" represents the probability that two of these people will share a birthday. \\ Verify the table given.}

6. Extend the table for $n$ to 50 .

7. What is the chance that, in a group of 5 people selected at random, two will have the same birthday?

8. What is the chance that, in a group of 35 people selected at random, two will have the same birthday?

9. At what point (how many people) are chances greater than $50 \%$ that two will share a birthday?

10. In a group of 50 , what is the probability that two or more will share a birthday?

$\underline{\text { Part B }}$

1. You are rolling two six sided number cubes. How many possible rolls are there?

HINT: Even though these rolls :: • $\quad$ - :8 are both ' 5 ', count them as two different possibilities.

2. Make a table of values, with column 1 being the sum of the two cubes on the roll, and column 2 being the number of ways this sum can occur.

3. Using the information from part (1) and (2), determine the probability for each roll, as a decimal, and place it in another column. Check your answer by summing the values. They should sum to?

4. Make a bar graph, with the "roll" along the horizontal and "probability" along the vertical.

5. Now we will simulate 50 rolls of the cubes, either using dice or MS Excel*. Record the results, and put it in a table

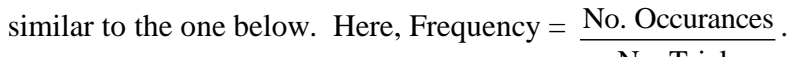

\section{No. Trials}

6. Why are the results different for the simulation in (5) than what was predicted in (3)?

7. Do another 50 simulations, and repeat part (5) for 100 simulations. Are the results closer to the predicted values? To what do you attribute this? 
*Using Excel to Simulate Cube Rolls:

1. Make a chart similar to the one below, where "Roll Number" goes from 1 to 50 .

\begin{tabular}{|c|c|c|c|c|}
\hline & A & B & C & D \\
\hline 4 & Roll Number & Cube 1 & Cube 2 & Sum \\
\hline 5 & 1 & 5 & 5 & 10 \\
\hline 6 & 2 & 2 & 1 & 3 \\
\hline 7 & 3 & 5 & 5 & 10 \\
\hline 8 & 4 & 3 & 6 & 9 \\
\hline 9 & 5 & 3 & 5 & 8 \\
\hline
\end{tabular}

2. In the cell for "Cube 1" and "Cube 2" type in "=RANDBETWEEN(1,6)". This will generate a random integer between 1 and 6 .

NOTE: If this function is not available, and returns the \#NAME? error, install and load the Analysis ToolPak add-in by going to the Tools menu, click Add-Ins. In the available list, select the Analysis ToolPak box, and click OK. If necessary, follow instructions in the setup program.

3. In the "Sum" column, add the values from "Cube 1" and "Cube 2" by using the cell references, i.e. "=B5+C5".

4. Copy the values for Row 5 all the way down until you have 50 simulations.

5. You can determine the number of times a value, say '2,' occurs in a list of numbers by typing

"=COUNTIF(range,criteria)" In this case, the range will be your Sum column. And criteria will be the value 2.

\section{District and State Standards Covered}

The CCSD Power standards for grades five through eight are broken up into the following six categories:

1. Numbers, number sense and computation

2. Patterns, functions and algebra

3. Measurement

4. Spatial relationships and geometry

5. Data analysis

6. Mathematical problem solving, communication, reasoning, and connections.

This course specifically addresses topics in each category. The previous course [1] stressed: mathematical notation, proportion, computation, estimation, linear regression, reflections, translations, finding relationships, and analyzing data. The course presented herein focuses on: spatial relationships, geometry, problem solving, reasoning, mathematical modeling, financial and economic analysis, and probability.

Table 1: Standards Covered in Projects

\begin{tabular}{|l|ccc|}
\hline & $\begin{array}{c}\text { No. of Standards } \\
\text { Addressed }\end{array}$ & $\begin{array}{c}\text { Total No. of } \\
\text { Standards }\end{array}$ & Percentage \\
\hline (1) Number Sense & 9 & 30 & $30 \%$ \\
(2) Patterns, Functions and Algebra & 12 & 26 & $46 \%$ \\
(3) Measurement & 6 & 16 & $38 \%$ \\
(4) Spatial Relationships and Geometry & 13 & 30 & $43 \%$ \\
(5) Data Analysis & 12 & 17 & $71 \%$ \\
(6) Problem Solving, etc & 36 & 52 & $69 \%$ \\
\hline
\end{tabular}

Table 1 is an outline of the number of standards covered with all the projects combined (not including class discussions). A list of these standards can be found at [15] and [16]. As can be seen from Table 1, the projects are heavy in the areas of "Problem Solving, Communication, Reasoning and Connections" (6), with more than 69\% of all standards addressed. In each category (1) through (6), over one third of all standards are covered in the projects. In 
total, over fifty percent of all CCSD Power Standards (grades five through eight) are covered within the context of these projects.

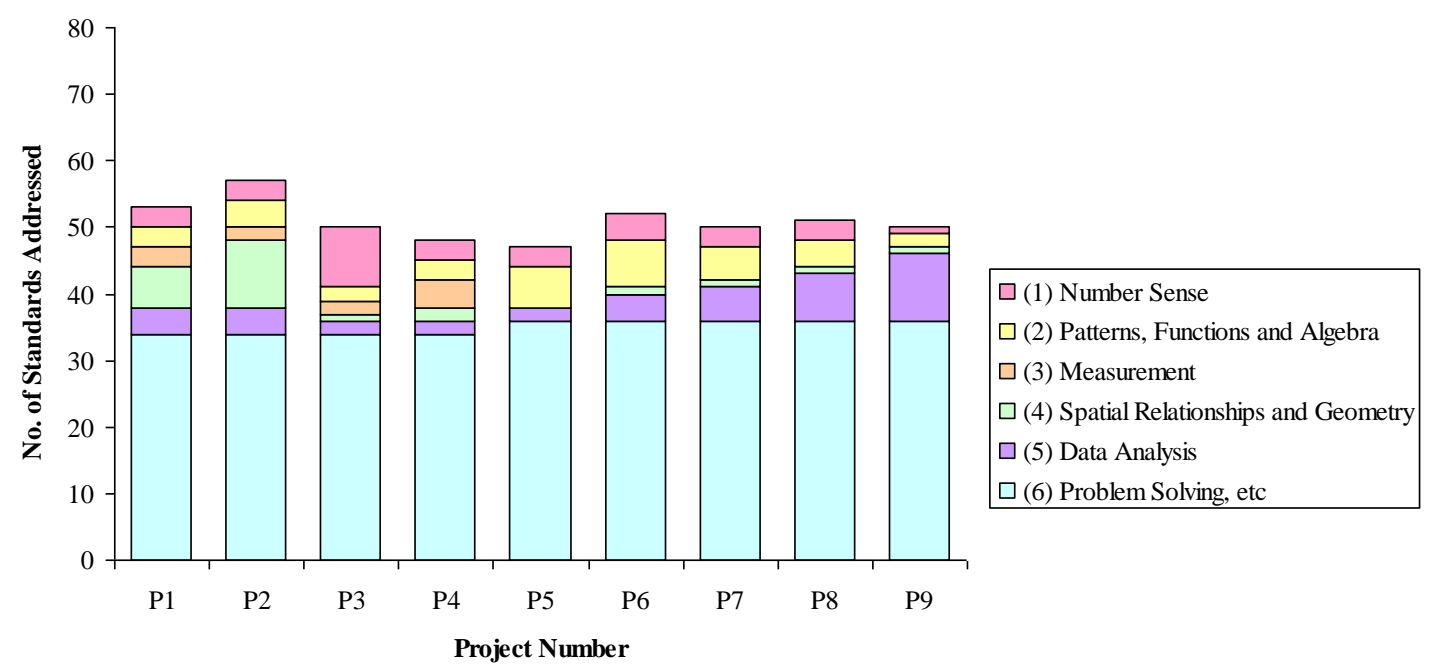

Figure 1: Number of Standards Addressed by Each Project

Figure 1 displays the number of standards addressed by each project alone. On average, each project addresses almost a third of all 171 CCSD Power Standards (grades five through eight) in all categories.

\section{CONCLUSION}

As the teaching and learning standards in mathematics across the country become more content driven, college level math courses for teachers must focus specifically on delivering mathematical content in a meaningful way. The nine projects presented in this paper not only assist in developing content understanding, but show teachers how to apply the content to student's lives.

Mathematics is everywhere, but is not usually recognized because it doesn't look like the algebra struggled through in school. It is the job of educators to demonstrate, to their communities, the relevance and importance of mathematics in every day life. It is time to embrace the learning and understanding of mathematics, and the projects presented here are a small step in achieving that goal.

\section{REFERENCE}

1. Using Student-Centered Projects to Teach Mathematics Content Standards to Middle School Teachers. Accepted, to appear in Journal of College Teaching and Learning.

2. Clark County School District. Mathematics and Science Partnership Program Proposal \#103. Grant submitted to the Nevada Department of Education. November 2003.

3. Nevada Mathematics Standards. Adopted March 2001. February 25, 2003 Edition.

4. Tirabassi, M. Foundations of Greek Geometry. February 2006 http://www.perseus.tufts.edu/GreekScience/Students/Mike/geometry.html.

5. Teachers Lab. Why Geometry is Important. February 2006 http://www.learner.org/teacherslab/math/geometry/across.html.

6. Berry J. and Nyman M. Introducing Mathematical Modeling Skills to Students and the Use of Posters PRIMUS, 8 No 2, 103-115, 1998. 
7. What American Teens \& Adults Know About Economics Executive Summary. National Council on Economic Education. April 2005 http://www.ncee.net/cel/WhatAmericansKnowAboutEconomics_051105ExecSummary.pdf.

8. Ingels, Steven J. and Mary U. O'Brien. The Effects of Economics Instruction in Early Adolescence. Theory and Research in Social Education 4 (Fall 1988): 279-294.

9. Seiter, David M. Teaching and Learning Economics. ERIC Clearinghouse for Social Studies/Social Science Education Bloomington IN. ED304396. March 1989 http://www.ericdigests.org/pre-9210/economics.htm.

10. Lee, Hea-Jin. Resources for Teaching and Learning about Probability and Statistics. ERIC Clearinghouse for Science Mathematics and Environmental Education Columbus OH. ED433219. May 1999 http://www.ericdigests.org/2000-2/resources.htm.

11. Falk, R. (1988). Conditional Probabilities: Insight and difficulties. In R. Davidson, \& J.Swift (Eds.), The proceedings of the second International Conference on Teaching Statistics. Victoria B.C.: University of Victoria.

12. Course Overview. October 2005 http://www.unlv.edu/faculty/bellomo/Sci620d/Topics.html.

13. Background and Information on Ecoli. March 2006 http://www.unlv.edu/faculty/bellomo/Sci620d/Projects/EColi.pdf.

14. Understanding Economics Data. March 2006 http://www.unlv.edu/faculty/bellomo/Sci620d/Projects/Project8.xls.

15. K-5 CCSD Power Standards. October 2005 http://www.ccsn.edu/education/Math_K-5PowerStandards.pdf.

16. 6-12 CCSD Power Standards. October 2005 http://www.ccsn.edu/education/Math6-12PowerStandards.pdf. 


\section{Notes}

